\title{
Numerical and Experimental Dynamic Contact of Rotating Spur Gear
}

\author{
ALI KAMIL JEBUR \\ DEPARTMENT OF MECHANICAL ENGINEERING \\ JAMIA MILLIA ISLAMIA NEW DELHI-110025, India \\ Tel: 91-97-1747-8987_E-mail: ali_kame1742002@yahoo.com
}

I.A.KHAN

DEPARTMENT OF MECHANICAL ENGINEERING

JAMIA MILLIA ISLAMIA NEW DELHI-110025, India

Tel: 91-11-2698-1259 Fax: 91-11-2698-1259 E-mail: iakhanjmi@yahoo.co.in

\author{
Y.NATH \\ DEPARTMENT OF APPLIED MECHANICS \\ INDIAN INSTITUTE OF TECHNOLOGY NEW DELHI-110016, India
}

Tel: 91-11-2659-1220Ｆax: 91-11-2658-1119Ｅ-mail: ynath@am.iitd.ac.in

Received: December 10, 2010

Accepted: January 10, 2011

doi:10.5539/mas.v5n2p254

\begin{abstract}
During the last century, there have been major developments in the technology of power transmission by gears. Numerical analysis contact stress of the spur gear tooth models by using ANSYS programming (point to point) and experimental work by using the stress-optical method (photo elasticity) are widely used today. This paper investigates the characteristics of an Involutes gear system including contact stresses between pair of the gears (surface to surface) for 3D and comparing the results with the experimental results. The experimental analysis established in new idea by using the D.C servomotor and planting the strain gages in the tooth of the gear (polyimide materials). The results of the numerical FEM analyses from ANSYS programming (surface to surface) and experimental analysis (D.C servomotor) are presented in order to calculate the contact stress. These stresses are compared between numerical and experimental results. Both results agree very well. This indicates that the experimental model is successful and leads to excellent results comparing with numerical results (ANSYS program) and equal (12.86 \%).
\end{abstract}

Keywords: Contact Stress, Finite Element Method, Spur Gear, Hertz

\section{Introduction}

Gearing is one of the most critical components in mechanical power transmission systems. Contact problems are highly nonlinear and require significant computer resources to solve. Contact nonlinearities occur when two or more components come into or out of contact with each other. In engineering applications, most contact processes are dynamic in a restrictive sense. Many of them can, however, be regarded as static for simplicity. By nature, contact phenomena always involve friction phenomena. However, friction effect may be neglected for simplicity in situations where frictional forces are sufficiently small. One may argue that the subject of contact mechanics started in 1882 with the publication of the classical work by Hertz. The Hertz theory is however restricted to frictionless contact and perfectly elastic solids. Finite element analysis of meshing gear pairs will be subject to non-linear contact analysis. In this situation, JIANDE WANG (Jiande Wang, 2003) investigated numerical methods for modeling the contact stresses of involutes spur gears in mesh, over the mesh cycle, which forms the major part of this work. Zeping Wei (Zeping Wei, 2004) investigated the characteristics of an involutes gear system including contact stresses, bending stresses, and the transmission errors of gears in mesh. The characteristics of involutes spur gears are analyzed by using the finite element method. C H Wink and A. L. Serpa (C. H. Wink and A. L. Serpa, 2005). Tooth contact deviations from the plane of action and their effects on gear transmission error are investigated. Tooth contact deviations come from intentional modification of involutes tooth surfaces such as tip and root profile relief; manufacturing errors such as adjacent pitch error, 
profile errors, misalignment and lead errors; and tooth elastic deflections under load, for example, bending and local contact deflections. Those deviations are usually neglected on gear tooth contact models. A procedure to calculate the static transmission error of spur and helical gears under loading is proposed. In the proposed procedure, contact analysis is carried out on the whole tooth surface, eliminating the usual assumption that tooth contact occurs only on the plane of action. Lead and profile modifications, manufacturing errors and tooth elastic deflections are considered in the calculation procedure. The method of influence coefficients is employed to calculate the tooth elastic deflections. Load distribution on gear meshing is determined using an iterative-incremental method. Results of some numerical examples of spur and helical gears are analyzed and discussed. The results indicate that the tooth contact deviations from the plane of action can lead to imprecision on the gear transmission error calculation if they are not take into account. Therefore, the proposed procedure provides a more accurate calculation methodology of gear transmission error, since a global contact analysis is done. Nilanjan Sarkar, Randy E. Ellis, Thomas N. Moore (Nilanjan Sarkar, Randy E. Ellis, Thomas N. Moore, 2006) Backlash is a common fault that occurs in geared mechanisms, and can produce inaccuracy or uncontrollability of the mechanism. It is shown that, by modeling backlash as microscopic impact, its presence can be detected and possibly measured using only simple sensors. The first stage of modeling establishes the need for the use of nonlinear elastic and damping forces in establishing the gear-teeth reaction force. The second stage of modeling used a detailed digital multi body simulation to develop and test the effectiveness of the proposed detection approach. Experiments verify the efficacy of the methodology in practice. Finally, the results can be quantified for a tested mechanism, indicating that this methodology may be useful for condition monitoring of industrial mechanisms. M. Amabili and A. Rivola (M., Amabili and A. Rivola 2008) the steadystate response and stability of the single degree of freedom (sdof) model of a pair of low contact ratio spur gears are studied. In the proposed model a time varying stiffness of the meshing tooth pairs and a viscous damping proportional to the meshing stiffness are considered. Gear errors of each meshing tooth pair are also included. Continuous closed form solution was obtained for any rotational speed where there is no tooth separation. Transition curves separating stable and unstable regions are computed by Hill innate determinant different meshing stiffness are considered and the incense of both damping and contact ratios are investigated. One of the advantages of the technique used is the speed and accuracy of the computation of the responses and transition curves. Results obtained by the numerical simulation of the steady-state responses of two different pairs of spur gears are satisfactorily compared to experimental results. V. Atanasiu, I. Doroftei (V. Atanasiu, I. Doroftei, 2009) presents a dynamic tooth load analysis of spur gears with addendum modification. The analytical model is developed to simulate the load sharing characteristics through a mesh cycle. The model takes into account the main internal factor of dynamic load as time-varying mesh stiffness and composite tooth profile error. The specific phenomenon of contact tooth pairs alternation during mesh cycle is integrated in this dynamic load modeling. A comparative study is included, which shows the effects of the factors with an important role in the way of the dynamic load variation. V. Spitas and T. Costopoulos. (Spitas. G. A. Papadopoulos. C. Spitas and T.Costopoulos, 2009) Investigate a comprehensive methodology for calculating load shearing in multiple gear tooth contact is presented based on the experimental stress-optical method of caustics. The technique is applied to a set of poly-methyl-methacrylate gears at various meshing positions covering a complete meshing cycle, including single and multiple gear tooth contact. The load shearing factor (LSF) is calculated using well-established mathematical formulae from the photographs of the transmitted caustics and the obtained results are compared with the pertinent international organization for standardization and American gear manufacturers association standards with which good agreement is verified

\section{The Finite Element Method of Contact Analysis: (Ramamurti, V., and Ananda, M, 1988).}

The finite element general equation can be described by:

$[\mathrm{M}]\{\mathrm{A}\}+[\mathrm{K}]\{U\}=\{F\}$

Where $[M]$ is the mass matrix, $[K]$ is the stiffness; $\{U\}$ is the displacement vector. $\{A\}$ is the acceleration vector, and $\{\mathrm{F}\}$ is the external load vector as in the standard finite element procedure.

It can be taken as the primary unknowns to be solved for Denoting the contribution of' contact forces to the load vector by $\{\mathrm{Fc}\}$, we can write,

$$
[\mathrm{M}]\{\mathrm{A}\}+[\mathrm{K}]\{\mathrm{U}\}=\{\mathrm{F}\}+\left\{F_{c}\right\}
$$

In eq. (2), $\left\{F_{c}\right\}$ is unknown and is to be calculated under the constraint given in eq. (3). With the finite element discretization, the kinematics constraint on contacting nodes can be put into the form,

$[\mathrm{Q}]\{\mathrm{U}\}+\{\mathrm{G}\}=0$ 
Where $\{\mathrm{G}\}$ is calculated from initial gaps of contacting nodes and $[\mathrm{Q}]$ is a coefficient matrix resulting from the finite element discretization.

In order to solve equations $(2,3)$, first determine the total number of contacting nodes, which are unknown until the solution is found. Thus, trial contacting nodes need to he used and iterations need to be carried out to find the true contacting nodes, at the same time, the contact condition must been forced to solve the unknown contact force, which necessitates a constraint method. If frictional effects are to be considered, a friction law governing the tangential contact force is required. Furthermore, both displacements and accelerations are unknowns in equations $(2,3)$. Therefore, a time integration method is also required for the solution.

With the use of advanced finite element techniques, no restriction is in principle necessary on the geometry, material properties, and deformation patterns contacting bodies. The versatility of the finite element method makes it possible to attack extremely complicated problems. Over the last few decades, great efforts have been devoted to the finite element study of contact problems. Remarkable progress has been made in both theoretical studies and engineering applications.

\section{How to Solve the Contact Problem}

In order to handle contact problems in meshing gears with the finite element method, the stiffness relationship between the two contact areas is usually established through a spring that is placed between the two contacting areas. This can be achieved by inserting a contact element placed in between the two areas where contact occurs.

There are two methods of satisfying contact compatibility: (i) a penalty method, and (ii) a combined penalty plus a Lagrange multiplier method. The penalty method enforces approximate compatibility by means of contact stiffness. The combined penalty plus Lagrange multiplier approach satisfies compatibility to a user-defined precision by the generation of additional contact forces that are referred to as Lagrange forces.

It is essential to prevent the two areas from passing through each other. This method of enforcing contact compatibility is called the penalty method. The penalty allows surface penetrations, which can be controlled by changing the penalty parameter of the combined normal contact stiffness (K. L. Johnson, 2003). If the combined normal contact stiffness is too small, the surface penetration may be too large, which may cause unacceptable errors. Thus the stiffness must be big enough to keep the surface penetrations below a certain level. On the other hand, if the penalty parameter is too large, then the combined normal contact stiffness may produce severe numerical problems in the solution process or simply make a solution impossible to achieve. For most contact analyses of huge solid models, the value of the combined normal contact stiffness may be estimated ANSYS as,

$$
K_{n}=f E h
$$

Where $f$ is a factor that controls contact compatibility. This factor is usually being between 0.01 and 100 . (ANSYS 6.5)

$$
\begin{aligned}
& E=\text { Smallest value of Young's Modulus of contacting material } \\
& h=\text { The contact length }
\end{aligned}
$$

The contact stiffness is the penalty parameter, which is a real constant of the contact element. There are two kinds of contact stiffness, the combined normal contact stiffness and the combined tangential or sticking contact stiffness. The element is based on two stiffness values. They are the combined normal contact stiffness $k$ and the combined tangential contact stiffness $k$. The combined normal contact stiffness $k$ is used to $\stackrel{n}{\text { penalize }}$ interpenetration between the two bodies, while the combined tangential contact stiffness $k^{n}$ is used to approximate the sudden jump in the tangential force, as represented by the Coulomb friction when sliding is detected between two contacting nodes. However, serious convergence difficulties may exist during the vertical loading process and application of the tangential load often results in divergence. A detailed examination of the model's nodal force during the vertical loading may indicate the problem. Not only are friction forces developing but they develop in random directions. This is due to Poisson's effect causing small transverse deflections of the nodes in the contact zone. These deflections are enough to activate the friction forces of the contact elements (Faydor L. Litvin, Alfonso Fuentes, J. Matthew Hawkins and Robert F.handschuh, 2001). The friction forces are developing in various directions because the generation of a tangential friction force facing right on one node would tend to pull the node on its left to the right. This would generate a friction force facing left on this node, pulling back on the other node. This continual tug-of-war causes the poor convergence. This problem is eliminated by applying a small rotation to the above cylinder model forces as it is displaced and loaded vertically. This rotation ensures that the friction forces would develop in the proper direction. 
The contact problem is addressed using a special contact element. A number of contact elements were available (two and three dimensional, spring and damper combinations). For the problem in hand, the element to be used is a two-dimensional, eight or six node structural solid and three-dimensional, twenty-node structural solid or layered solid, and surface-to-surface contact element. The fill description of the elements properties are shown below. The area of contact between two or more bodies is generally not known in advance. It may be applied to the contact of solid bodies for static or dynamic analyses, to problems with or without friction, and to flexible-to-flexible or rigid-to-flexible body contact.

\section{3D Contact element description}

The element of three dimensions to be used from ANSYS library is SOLID186. SOLID186 is a higher order 3-D 20-node solid element that exhibits quadratic displacement behavior. The element is defined by 20 nodes having three degrees of freedom per node: translations in the nodal $\mathrm{x}, \mathrm{y}$, and $\mathrm{z}$ directions. The element supports plasticity, hyper elasticity, creep, stress stiffening, large deflection, and large strain capabilities. It also has mixed formulation capability for simulating deformations of nearly incompressible elastoplastic materials, and fully incompressible hyper elastic materials.

The geometry, node locations, and the element coordinate system for this element are shown in Figure. (1). the contact algorithm of FEM computer program (ANSYS program) requires definition of contacting surface. To define a contact pair completely, contact and target element have to be referred to same characteristic parameters. The contact element 174 and target 170 with three nodes are used as a contact surface-to-surface in the present analysis as shown in Fig (2):-

\subsection{Contact174 3-D 8-Node Surface-to-Surface Contact}

CONTA174 is used to represent contact and sliding between 3-D "target" surfaces (TARGE170) and a deformable surface, defined by this element. The element is applicable to 3-D structural and coupled field contact analyses. This element is located on the surfaces of 3-D solid or shell elements with midside nodes (SOLID87, SOLID90, SOLID92, SOLID95, SOLID98, SOLID122, SOLID123, SOLID186, SOLID187, SOLID191, SOLID226, SOLID227, SOLID231, SOLID232, VISCO89, SHELL91, SHELL93, SHELL99, SHELL132, SHELL281, and MATRIX50). It has the same geometric characteristics as the solid or shell element face with which it is connected (see Figure 174.1: "CONTA174 Geometry" below). Contact occurs when the element surface penetrates one of the target segment elements (TARGE170) on a specified target surface. Coulomb and shear stress friction is allowed. This element also allows separation of bonded contact to simulate interface delimitation. The geometry and node locations are shown in Fig. (3). The element is defined by eight nodes (the underlying solid or shell element has midside nodes). It can degenerate to a six node element depending on the shape of the underlying solid or shell elements. If the underlying solid or shell elements do not have mid side nodes, use CONTA173 (you may still use CONTA174 but you must drop all mid side nodes).

\subsection{Targe170 3-D Target Segment}

TARGE170 is used to represent various 3-D "target" surfaces for the associated contact elements (CONTA173, CONTA174, CONTA175, CONTA176, and CONTA177). The contact elements themselves overlay the solid, shell, or line elements describing the boundary of a deformable body and are potentially in contact with the target surface, defined by TARGE170. This target surface is discretized by a set of target segment elements (TARGE170) and is paired with its associated contact surface via a shared real constant set. You can impose any translational or rotational displacement, temperature, voltage, and magnetic potential on the target segment element. You can also impose forces and moments on target elements. For rigid target surfaces, these elements can easily model complex target shapes. For flexible targets, these elements will overlay the solid, shell, or line elements describing the boundary of the deformable target body. The geometry and node locations are shown in Fig. (4).

\section{Experimental Work:}

By considering the same parameter of spur gear model analyzed numerically in table (1) as a standard model, three practical model of polyimide spur gear will be designed. See figure (5).Also, to be discuss the advantages and the disadvantages of each case will be discuss, logically as an engineering sense and experimentally by examining the gear design parameters (number of teeth with module) of three practical model of polyimide spur gear which will be built specially for gear shape problem. Strain gages are planting in limited point (three points of contact position) in the gear tooth of each case in order to measuring the strain (and converted to stress by using strain meter. see figure (6). 
In motion-control systems, it is often necessary to convert rotational motion into translation. Gear train, lever, or timing belt over a pulley is a mechanical device that transmits energy from one part of the system to another in such a way that force, torque, speed, and displacement may be altered. These devices can also be regarded as matching device used to attain maximum power transfer. D.C servomotor will be applied in order to found the contact stress (by using strain gage which is planting in gear tooth and get the strain from the strain meter and convert the results from strain to stress in order to achieve contact stress analytically) for three practical model of polyimide spur gear and compare the experimental results together with numerical analysis (ANSYS program). All portion of D.C servomotor are shown in figure (7).

\section{Results and Discussion:}

In this section, symmetrical contact spur gear teeth with different gear design parameters and without profile correction are investigated. Table (1).

Also, this section contains comparisons of the numerical and theoretical results obtained from the available published results and with the results of ANSYS package, Ver. (6.5), and this section investigates the characteristics of an involutes gear system including contact stresses.

The material used for models is polyimide with modulus of elasticity (E), yield stress ( $\sigma y)$, ultimate stress ( $\sigma u)$, material density $(\rho)$ and Poisson's ratio $(v)$ as follows:-

$E=3 * 10^{9}\left(\mathrm{~N} / \mathrm{m}^{2}\right), \quad \sigma y=55 * 10^{6}\left(\mathrm{~N} / \mathrm{m}^{2}\right), \quad \sigma u=80 * 10^{6}\left(\mathrm{~N} / \mathrm{m}^{2}\right) . \quad$ and $\quad v=0.3$

6.1 Discussions of Contact Analysis Results:

One case of table (1) has been accomplished in Fig. (8) To represent the sample of the nodal solution stress (Von Mises), with different contact position, were plotted using ANSYS package, the von Mises criterion is best applied and best understood when used to predict the onset of yielding in a structure where the material behaves in a ductile fashion.

The variation of the tooth maximum contact stress with the contact position for different gear design parameters is shown in Fig. (9). The effect of different gear design parameters (number of teeth with module) shown in Fig.(9-a), Fig (9-b) and (9-c) respectively for both numerical and experimental results.

Fig (9) show also the variation of the contact stress with contact position between numerical by using finite element analysis (ANSYS program) and experimental by using D.C servomotor with strain meter (by planting strain gage in gear tooth), for all cases of table. (1).

The results of experimental work (D.C servomotor) are nearly so much with numerical results (ANSYS program) for 3D.

The results of contact stress analysis indicates that increasing the geometrical parameters (number of teeth with module) lead to improve the tooth contact stress, with the contact position, because the increasing of the geometrical parameters will results in an increase of the tooth stiffness which leads to decrease the tooth contact stress.

\section{Conclusions:}

The main conclusions obtained from the present work can be summarized as follows: -

1)- Table. (2) Shown that a FEA model (surface to surface) could be used to simulate contact between two bodies accurately by verification of contact stresses between two gears in contact and comparison between these results with experimental work. The different of the results between numerical and experimental are very small and equal (12.86\%). Therefore the model of experimental work (D.C servomotor with strain meter) by planting strain gage in limited point of gear tooth is successfully.

2)- This new experimental model prove that we can get the contact stress of spur gear and any type of gear dynamically by planting a strain gage in gear tooth, also we can compare this results with numerical analysis (surface to surface) not ( point to point) like in old papers.

3)- The module has the greater effect on the behavior of the tooth contact stresses. Decreasing the module leads to increase in the contact stress.

4)- Increasing the spur gear design parameters (number of teeth with module) leads to improvement in the tooth strength by increasing the thickness of the critical section which results in increasing the area of tooth critical section and makes it able to withstand higher loads. 


\section{References}

ANSYS 6.5, Structural Analysis Guide.

C. H. Wink and A. L. Serpa. (2005). Investigation of Tooth Contact Deviations from the Plane of Action and Their Effects on Gear Transmission Error, State University of Campinas, Brazil, I. Mech. E. Vol. 219 Part C: J. Mechanical Engineering Science, PP.501-509.

Faydor L. Litvin, Alfonso Fuentes, J. Matthew Hawkins and Robert F.handschuh. (2001). Design, Generation and Tooth Contact Analysis (TCA) of Asymmetric Face Gear Drive With Modified Geometry, NASA Center for Aerospace Information.

Jiande Wang. (2003). Numerical and Experimental Analysis of Spur Gears in Mesh, PhD Curtin University of Technology September.

K. L. Johnson. (2003). Contact Mechanics, Cambridge University Press, Ninth prints.

M., Amabili and A. Rivola. (June 2008). Dynamic Analysis of Spur Gear Pairs: Study-State Response and Stability of the SDOF Model with Time-Varying Meshing Damping, University of Bologna, Italy, Mechanical Systems and Signal Processing, PP.375-390.

Nilanjan Sarkar, Randy E. Ellis, Thomas N. Moore. (2006). Backlash Detection in Geared Mechanisms: Modeling, Simulation, and Experimentation, Queen's University, Kingston, Canada, I. Mech. E. Vol. 220 Part K: J. Multi-body Dynamics, PP.273-282.

Ramamurti, V., and Ananda, M. (1988). Dynamic Analysis of Spur Gear Teeth, Indian Institute of Technology, India, Journal of Computers and Structures, Vol.29, No.5, PP.831-843.

Spitas. G. A. Papadopoulos. C. Spitas and T.Costopoulos. (2009), Experimental Investigation of Load Sharing in Multiple Gear Tooth Contact Using the Stress-Optical Method of Caustics, Journal Compilation, doi:10.1111/j.PP.1475-1305.2008.00558.x.

V. Atanasiu, I. Doroftei. (2009). Dynamic Contact Loads of Spur Gear Pairs with Addendum Modifications, Technical University of Lasi, Romania, Journal of Mechanical and Environmental Engineering.

Zeping Wei. (2004). Stresses and Deformations in Involutes Spur Gears by Finite Element Method, M.Sc University of Saskatchewan, Canada.

Table 1. Various geometrical properties for contact spur gear studied cases

\begin{tabular}{|c|c|c|c|}
\hline \multirow{2}{*}{ Case no } & \multicolumn{3}{|c|}{ Gear Tooth Characteristics (2D) } \\
\cline { 2 - 4 } & $\begin{array}{c}\text { Pressure Angle } \\
\left(\phi_{o}\right)\end{array}$ & $\begin{array}{c}\text { Number of } \\
\text { Teeth (N) }\end{array}$ & Module (mo) mm \\
\hline 1 & 20 & $(30-30)$ & 4 \\
\hline 2 & 20 & $(25-50)$ & 2 \\
\hline 3 & 20 & $(20-60)$ & 3 \\
\hline
\end{tabular}

Table 2. Verification test for contact stress between (22D and 3D) ANSYS program

\begin{tabular}{|c|c|c|}
\hline \multicolumn{2}{|c|}{ Contact Stress (Mpa) } & \multirow{2}{*}{ Percentage Error (\%) } \\
\cline { 1 - 2 } Experimental work (3D) & ANSYS Program (3D) & \\
\hline 27.723 & 24.158 & $12.86 \%$ \\
\hline
\end{tabular}




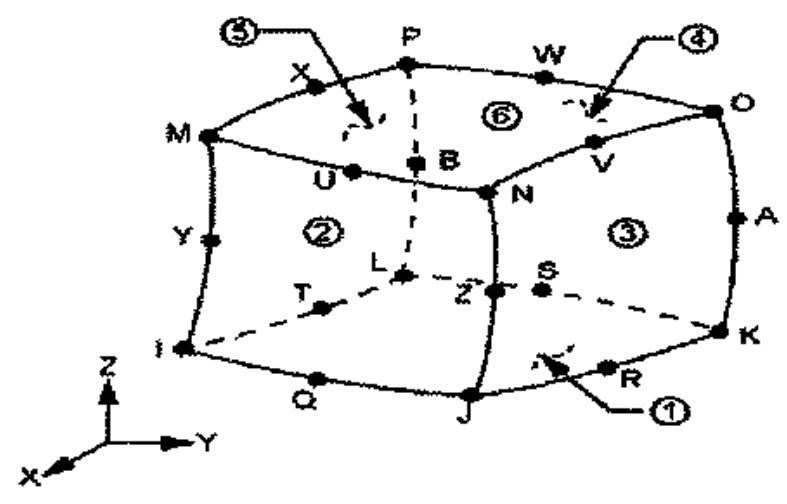

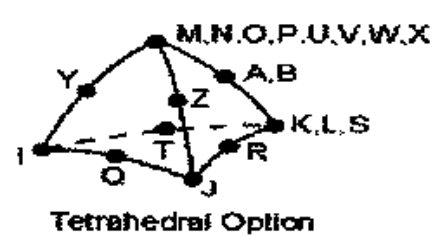
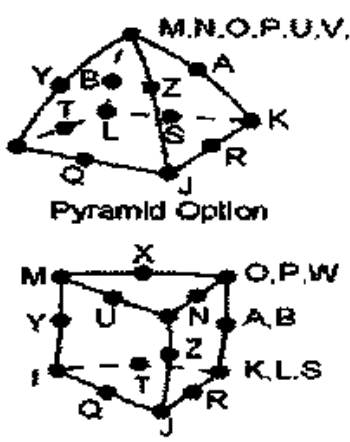

Prisan Option

Figure 1. Geometry of SOLID186

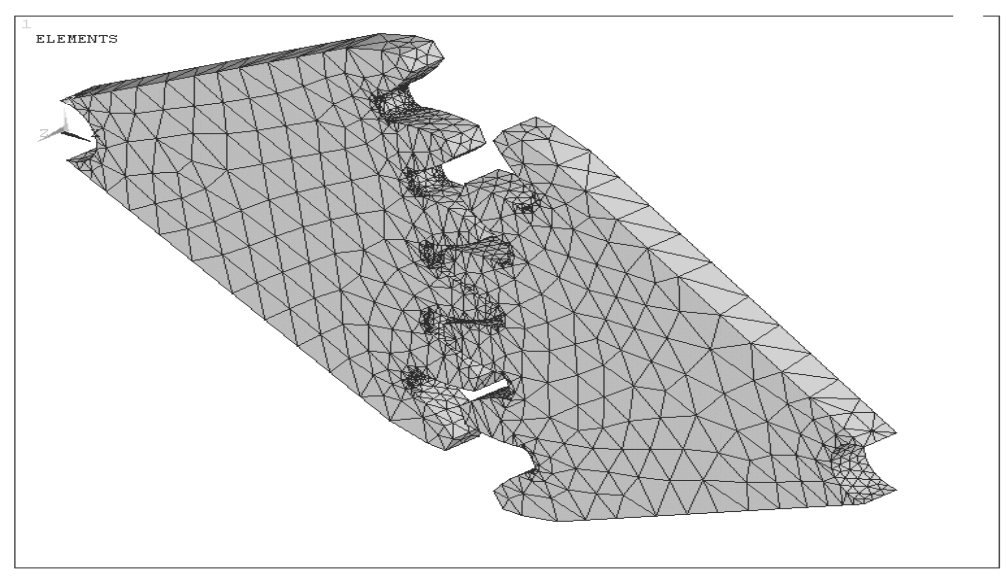

Figure 2. 3D Contact Gear

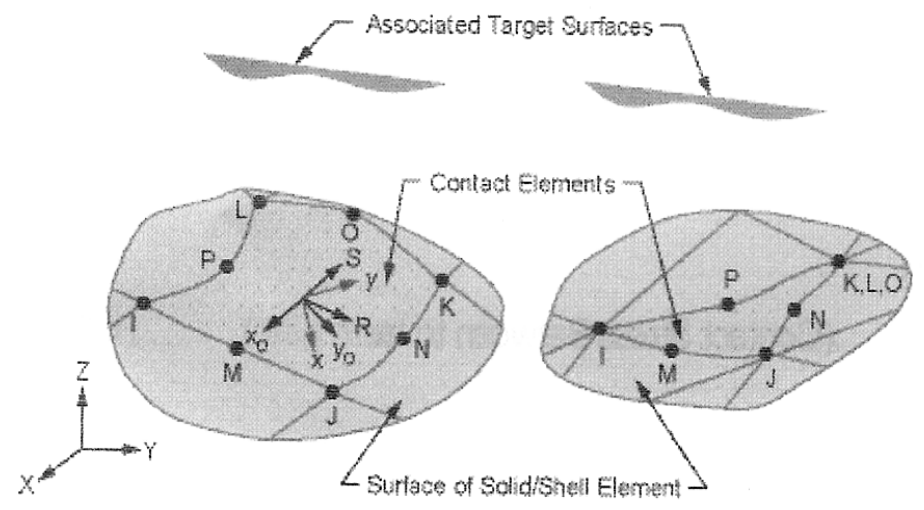

Figure 3. Geometry of contact 174 


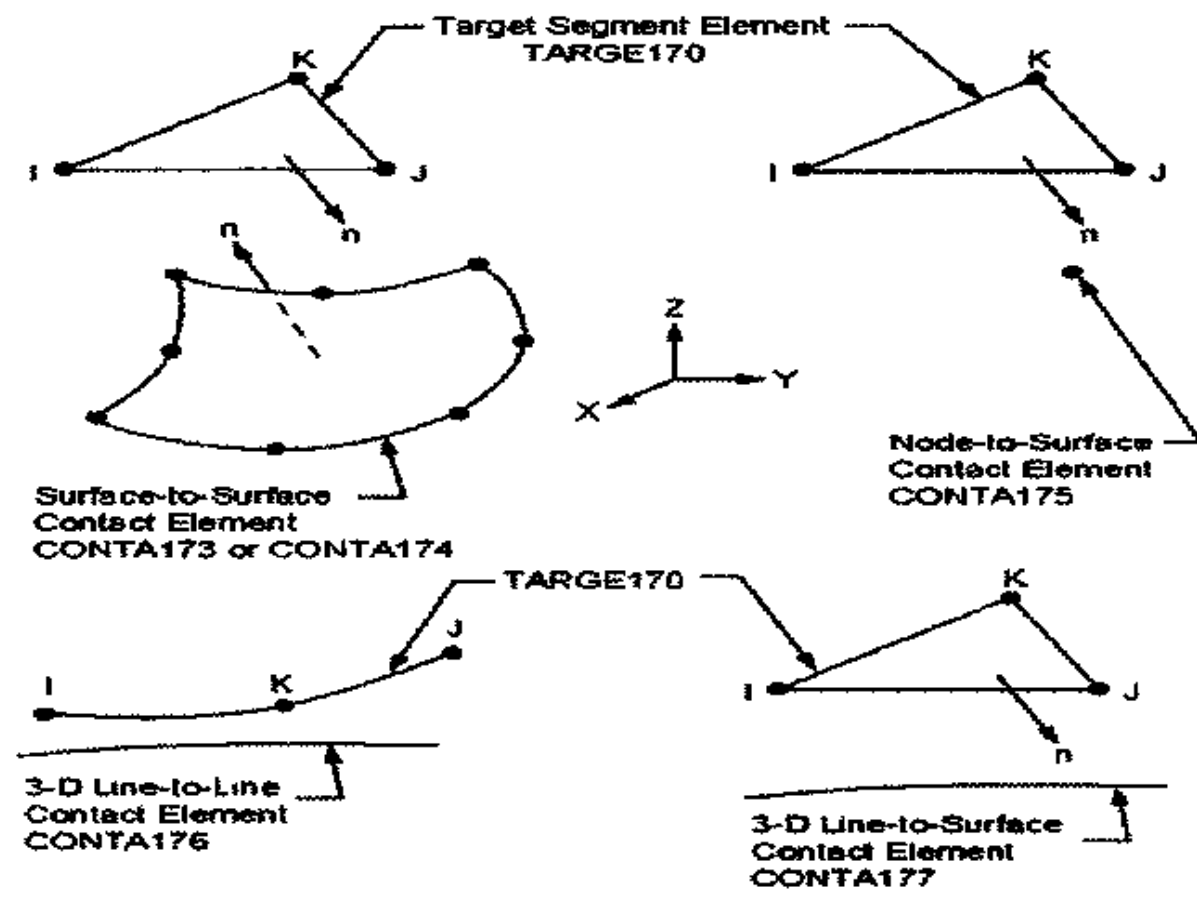

Figure 4. Geometry of target 170
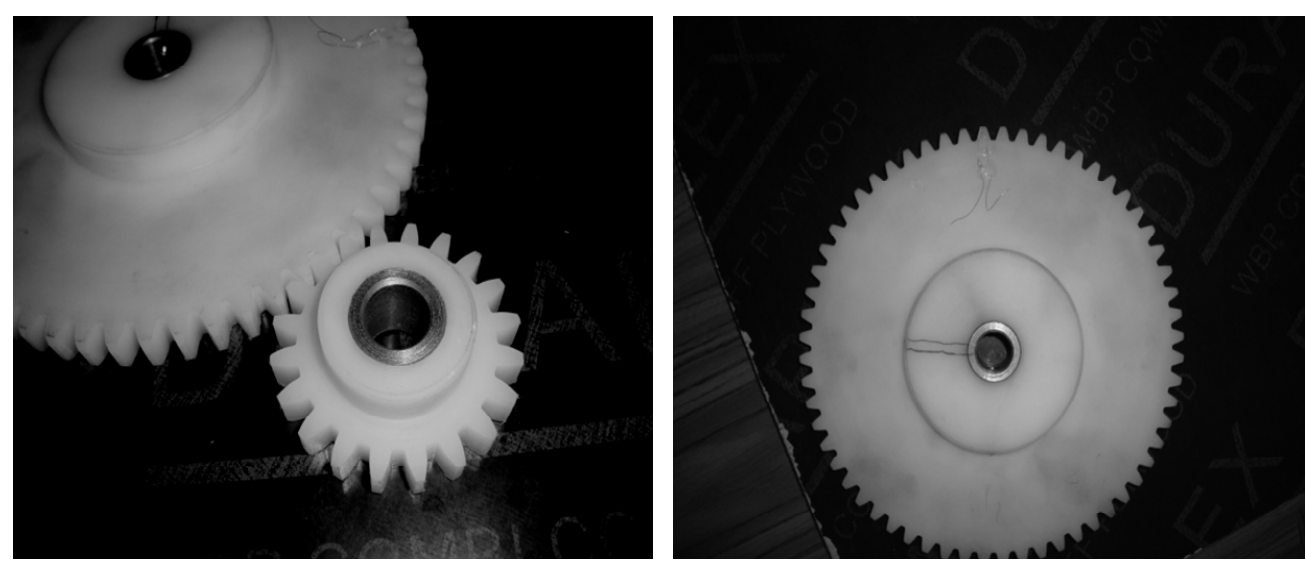

Figure 5. practical model of polyimide spur gear
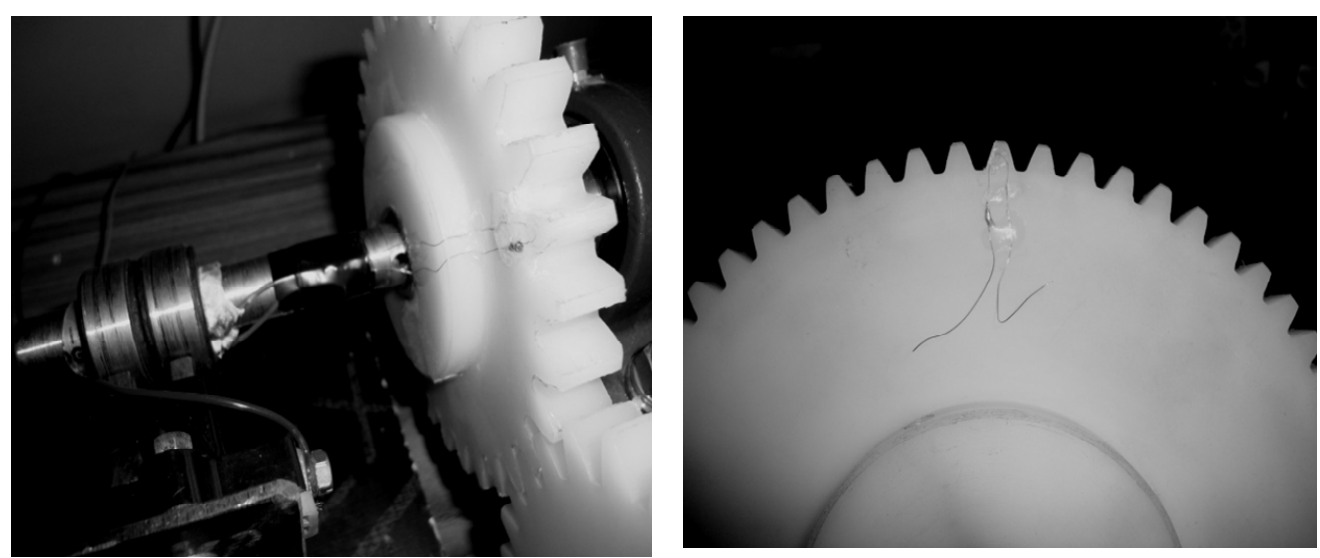

Figure 6. Strain gage which is planting in spur gear tooth 


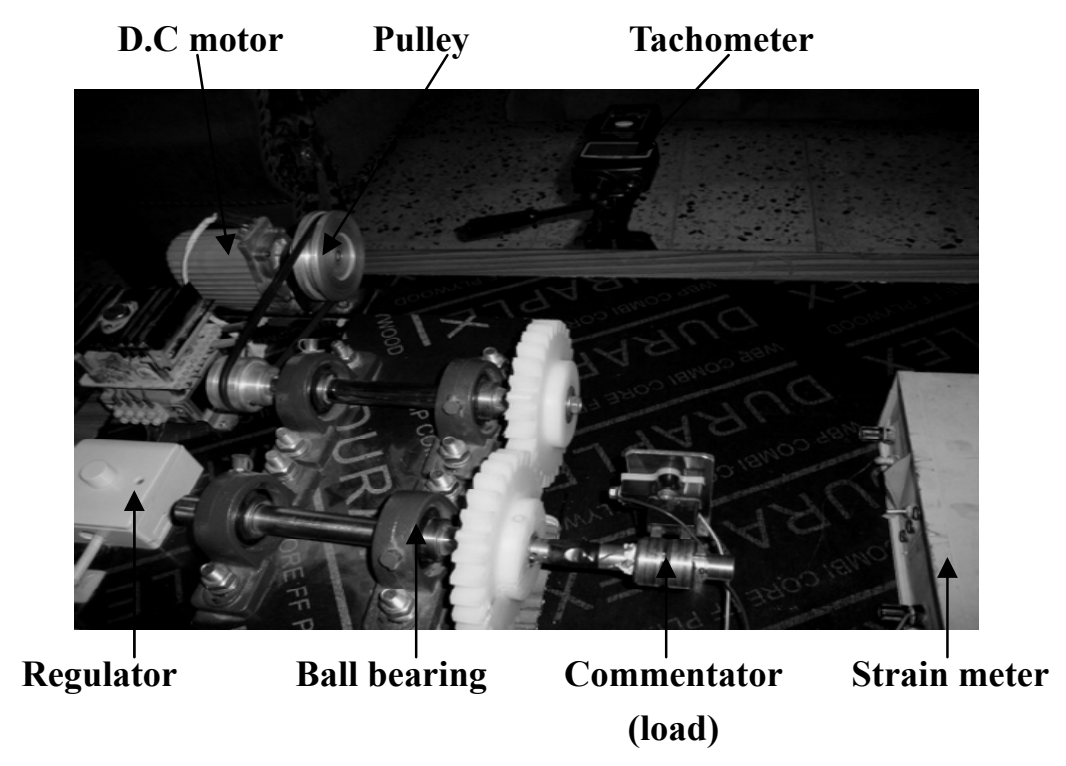

Figure 7. Experimental set - up (D.C servomotor)
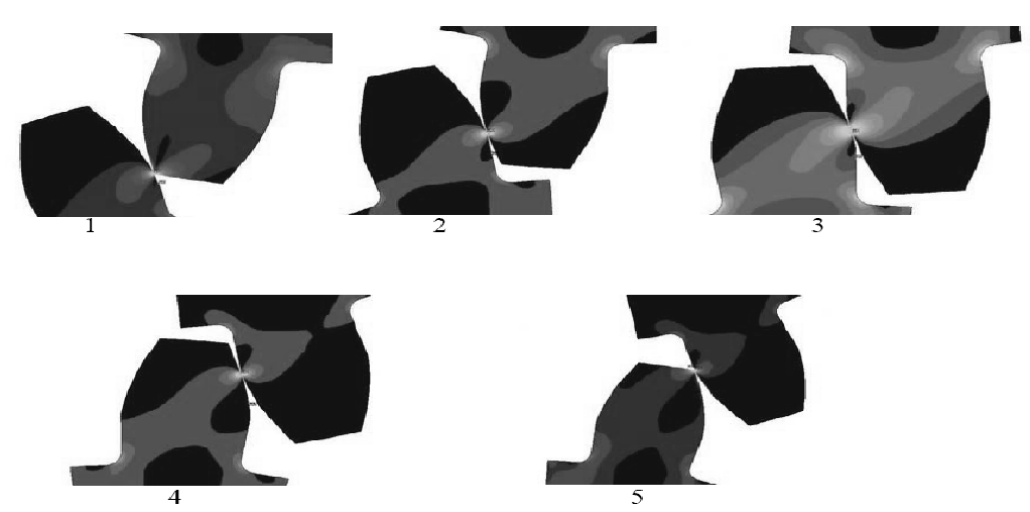

Figure 8. Contact stress (Von Mises), with different contact position

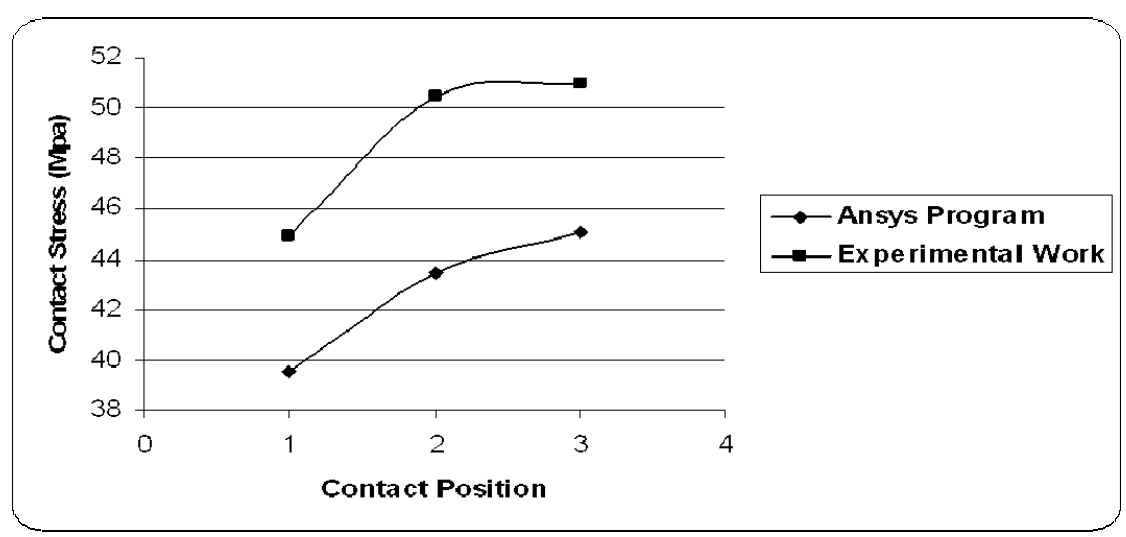

(a) Variation of contact stress with contact position for two gears ( $\mathrm{Np}, \mathrm{Ng}=30)$ case (1). 


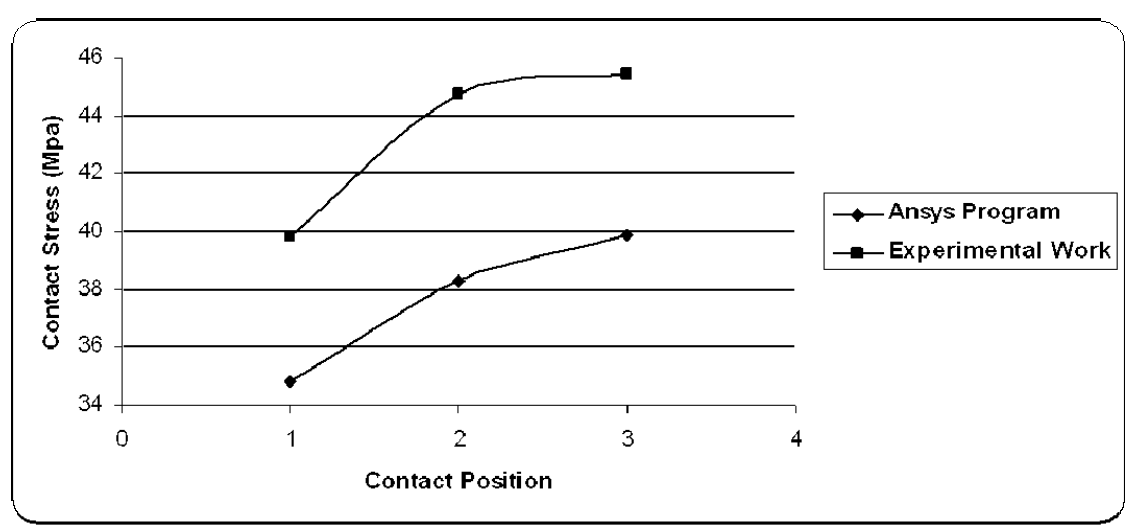

(b) Variation of contact stress with contact position for two gears ( $\mathrm{Np}=25, \mathrm{Ng}=50)$ case (2).

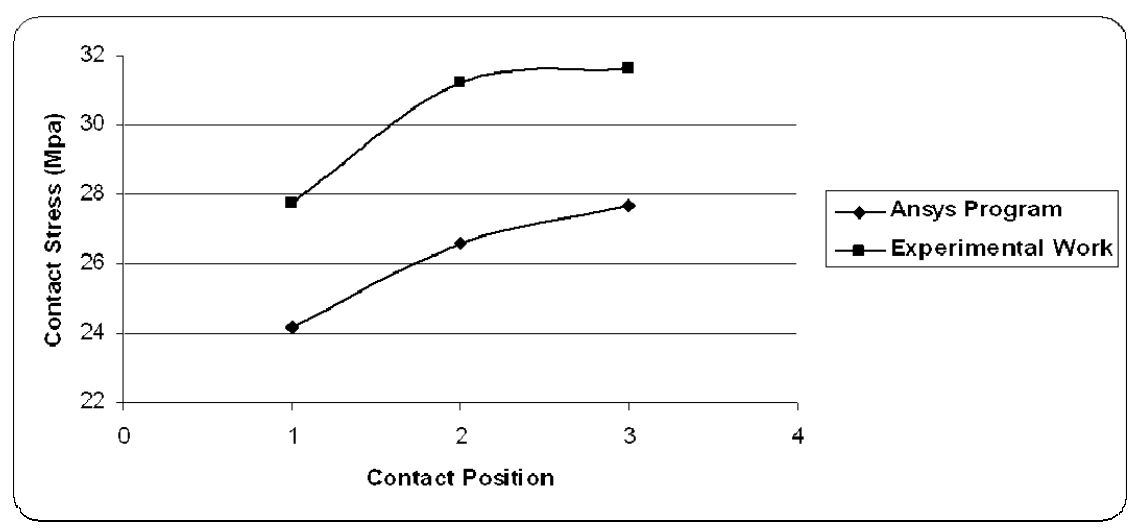

(c) Variation of contact stress with contact position for two gears $(\mathrm{Np}=20, \mathrm{Ng}=60)$ case (3).

Figure 9. Variation of contact stress with contact position between (2D and 3D) ANSYS program 